\title{
Shear Failure Criterion and Constant Volume Ring Shear Testing Method for Clayey Soil
}

\author{
Rafig Azzam \\ RWTH Achen University, Aachen, Germany \\ Email: azzam@lih.rwth-aachen.de
}

Received 21 July 2016; accepted 22 August 2016; published 25 August 2016

Copyright ( 2016 by author and Scientific Research Publishing Inc.

This work is licensed under the Creative Commons Attribution International License (CC BY). http://creativecommons.org/licenses/by/4.0/

(c) (i) Open Access

\begin{abstract}
This paper discusses the shortcomings of the traditional Coulomb shear criterion and the direct shear-box testing method used for clayey soil and presents a modified shear criterion that considers the elasto-plastic behavior of cohesive soil. This modified approach involves direct shear testing under constant volume, a method that has been developed by the author. A modified ring shear apparatus and the theory behind the shear criterion and its implication for slope stability analysis are then discussed and the results of investigated tuffitic clayey sediments are presented. The results show that the presented new shear criterion does not consider the cohesion as material constant, but rather it depends on the void ratio. In this case, the stress state and the consolidation status and thus the elasto-plastic behavior of the clayey soil are considered.
\end{abstract}

\section{Keywords}

Shear Criterion, Shear Testing Procedure, Shear Parameter, Ring Shear Testing, Slope Stability Analysis

\section{Introduction}

Coulomb Shear Criterion is popular because it is simple and can be established by direct shear testing. However, this criterion has severe shortcomings with regard to the behavior of cohesive soil, especially because it considers the cohesion as constant soil parameter. Prediction of the relevant behavior of soil and the evaluation of its properties are a prerequisite for examining the economy and safety of earth structures. Although the evaluation of the mechanical properties of soil has been primarily based on extensive laboratory tests, experience has shown in the past that shear strength parameters, as determined in standard laboratory tests, can easily lead to 
incorrect assessments of the stability of deep cut slopes in clays. In some cases, this discrepancy can be eliminated by changing the conditions under which the laboratory tests are being carried out.

However, it is often the case that the shear parameters and theoretical criteria on which they are based are irrelevant to the problem. One of the major reasons is that the complex behavior of the soil has been described through over-simplified models and mathematical equations. The behavior of clayey soil for example is neither purely elastic nor fully plastic, but is rather elasto-plastic which may in some cases be very complex. Since only the plastic deformation causes changes in the properties of soil, it is mostly this aspect that is of interest.

Shear box tests are still popular for establishing the shear strength parameters of cohesive soil, since they are easy and economical to perform. However, as will be shown below, the current shear strength criteria based on direct shear testing methods are not adequate, because they do not consider the elasto-plastic behavior of soil and the changes of the mechanical properties associated with it. Against this background and in acknowledgement of the popularity of direct shear box testing, efforts were directed towards the development of more adequate shear strength criteria accompanied with a modified direct shear testing method. An account of these efforts is given in this paper.

\section{Historical Development of Direct Shear Box Testing}

Coulomb presented in 1776 a fundamental paper discussing the shear strength of soil [1]. He considered the soil as a homogeneous, inelastic material, which breaks into rigid blocks. Coulomb attributed the shear strength along a fracture plane to a normal-stress-dependent friction term and to a cohesion term. He established a linear relationship between the normal force and the tangential force as reflected in Equation (1) and Figure 1.

Coulomb criterion:

$$
\tau=c+\sigma_{n} \cdot \tan \varphi
$$

Cohesion was defined by Coulomb as the part of shear strength, which is dependent upon the shape of the fracture as well as the amount and size of the grains which are being separated during the fracturing process. Later, in 1850, Collin investigated the influence of water content on the cohesion of the soil [2].

The predecessor of the modern shear box apparatus was designed and constructed in 1925 by Krey [3]. Using the Krey-apparatus, Tiedemann carried out shear tests on clay specimens in 1932 [4]. Because of the fast shear rate under which the tests were performed, these tests can be classified as CU-tests. The test results showed that the shear strength of equally surcharged specimens fit on one failure envelope whilst the lines for specimens with different surcharge pressures are parallel (Figure 2).

Tiedemann developed from his tests a new shear strength criterion:

$$
\tau=\left(\sigma_{\text {sur }} \cdot \tan \varphi_{c}\right)+\sigma_{n} \cdot \tan \varphi \text { for } \sigma_{n}<\sigma_{\text {sur }}
$$

with $\sigma_{n}$ is equal to actual normal stress during the shearing;

$\sigma_{\text {sur }}$ is equal to surcharge; max. past consolidation stress;

$\sigma_{s u r} \cdot \tan \varphi_{c}$ is equal to cohesion.

Since $\varphi_{c}$ is invariant for a certain type of soil, the cohesion is a function of the surcharge. That implies plas-

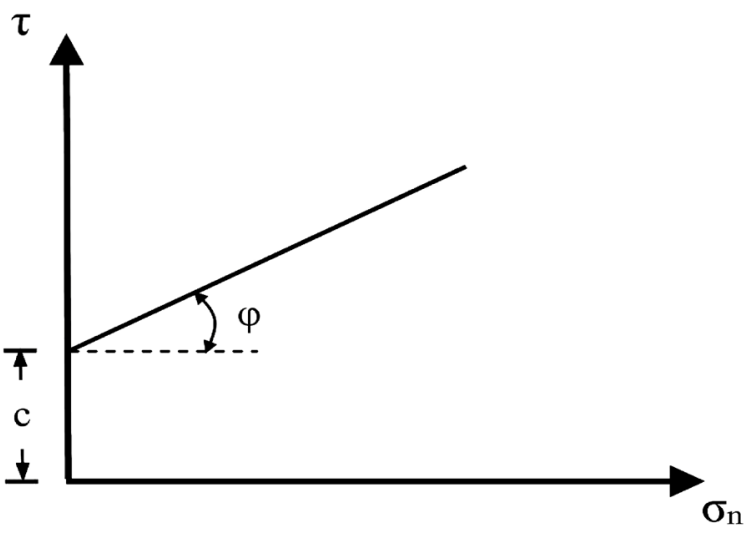

Figure 1. Definition of the coulomb criterion. 

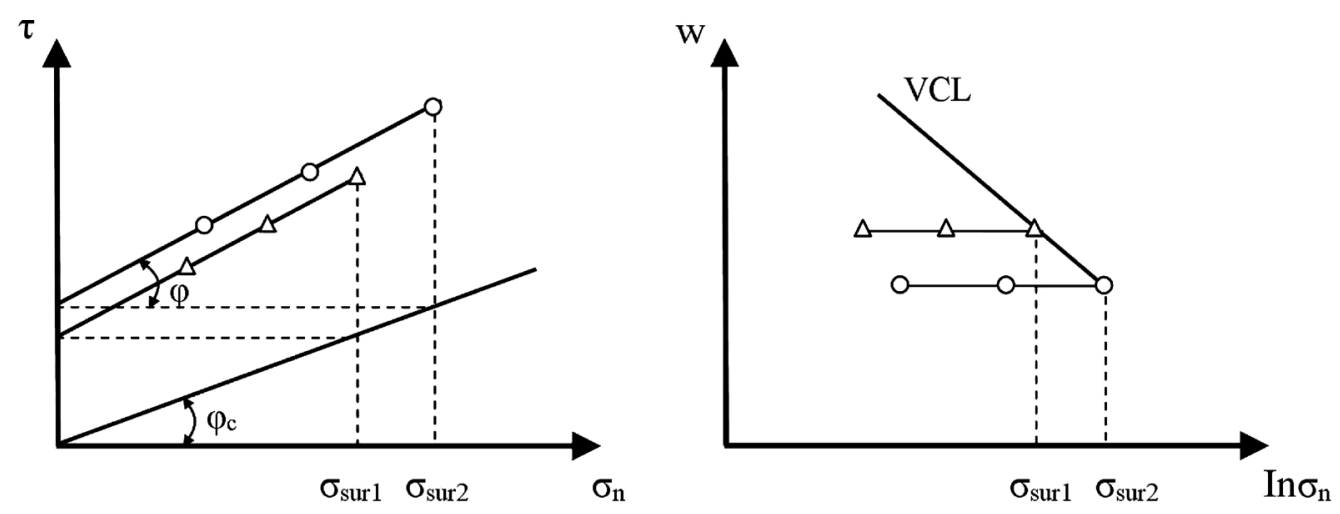

Figure 2. Definition of the Tiedemann criterion.

tic behavior for the soil. However, Tiedemann criterion describes the shear strength of soil intern of total stresses. Later, in 1935 Terzaghi presented his concept of effective stresses:

$$
\sigma_{\text {tot }}=\sigma_{\text {eff }}+u
$$

with: $\sigma_{\text {tot }}$ is equal to total stresses;

$\sigma_{\text {eff }}$ is equal to effective stresses;

$u$ is equal to pore pressure.

Another shear strength criterion was developed by Hvorslev in 1937 [5] [6]. He carried out shear tests on saturated and consolidated clay specimens in which time was allowed for full swelling before very slow shearing. Therefore, the tests can be interpreted in terms of effective stresses. Hvorslev considered the water-content in the shear plane before and after shearing. He established that normally consolidated specimens contract whilst over-consolidated specimens dilate. Furthermore, the relationship of water content to effective stress after shearing is of the same form as that before shearing (Figure 3).

Hvorslev found that the values for shear strength of specimens, which have equal water content after the shearing can be plotted on one line in the shear diagram, whilst the lines were parallel for different water content (Figure 4).

He presented a new criterion in 1937:

$$
\tau=\sigma_{n} \cdot \tan \varphi_{0}+V \cdot \exp \left(-B \cdot w_{0}\right)
$$

where $\sigma_{n}$ is equal to effective stresses;

$w_{o}$ is equal to water content;

$B$ is equal to slope of the VCL (virgin compression line);

$V$ is equal to constitutive constant.

This criterion considers the friction angle as a specific material constant and the cohesion as a function of water content. The soil behaves elasto-plastically.

Subsequently in 1949 Ohde modified the criterion of Tiedemann and presented a new criterion in two parts [7]:

$$
\begin{aligned}
\tau & =\tan \varphi_{s} \cdot \sigma_{n} \quad \text { (normal-consolidated) } \\
\tau & =\tan \varphi \cdot \sigma_{n}+\chi \cdot \sigma_{\text {sur }} \quad \text { (over-consolidated) }
\end{aligned}
$$

where $\chi$ is invariant and equal to $\sigma / \sigma_{\text {sur }}$.

This criterion recognizes the fact that the soil behaves plastically and has two different angles of internal friction.

Ohde's criterion has been applied ever since. Only a new sign for the effective stresses has been introduced by Skempton and Bishop in 1951 [8]. They rewrote Equation (6):

$$
\tau=\sigma_{n}^{\prime} \cdot \tan \varphi^{\prime}+c^{\prime}
$$

\subsection{Shortcomings of the Traditional Shear Box Texting Method and Implication in Slope Stability Analysis}

According to the investigations of soil behavior carried out by Hvorslev, Roscoe, Scofield and Wroth, the soil 


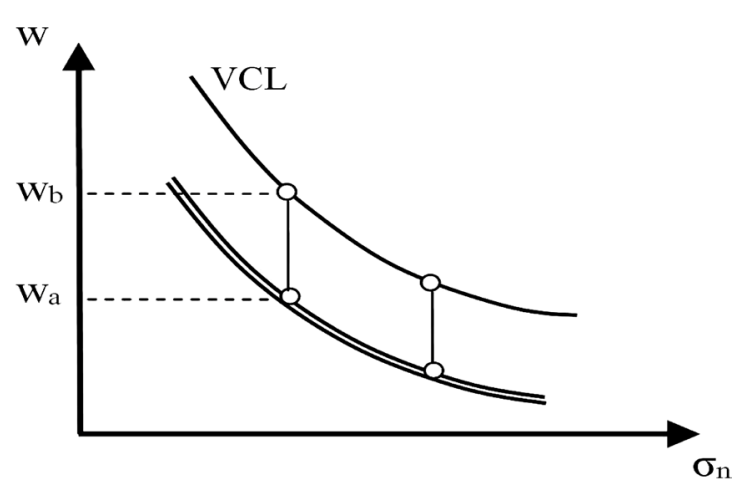

Figure 3. Water content versus effective normal stresses before and after shearing.
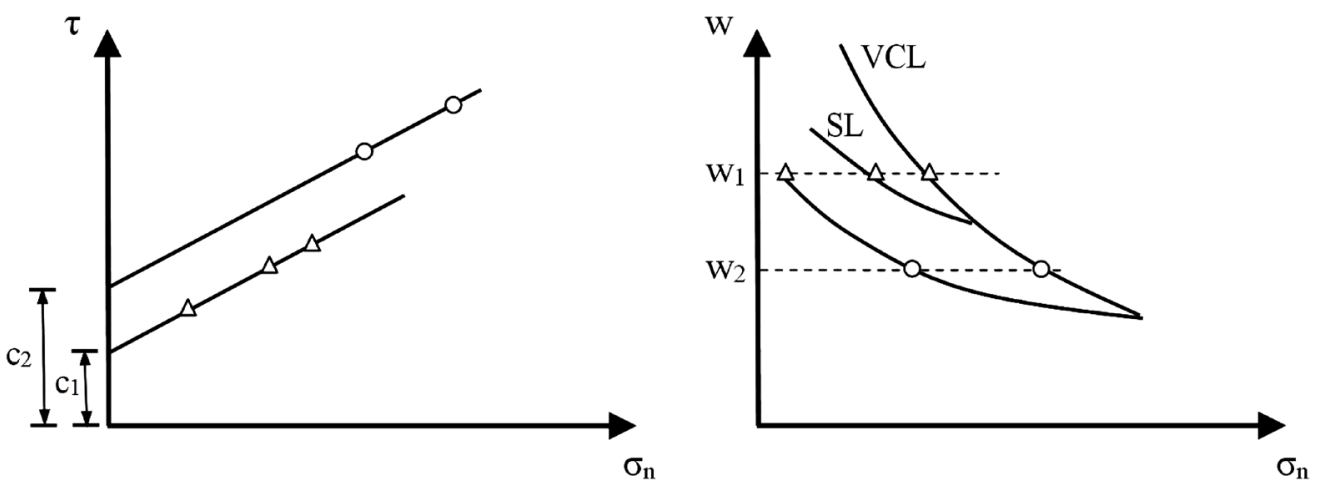

Figure 4. Definition of the Hvorslev criterion.

behaves elasto-plastically under effective stresses. The cohesion of saturated soil is a function of its water content. But since the water content is proportional to the void ratio at saturation, the cohesion is also a function of the void ratio. That means that two specimens with different degrees of over-consolidation have different void ratios and thus their respective cohesions are varied. However, shear box tests have traditionally been carried out without considering the state of over-consolidation of the clay. This introduces inconsistencies, which may be illustrated by the following hypothetical example. Consider two soil specimens, which have been taken from the same depth and are being tested in the shear box under different normal stress levels. Since both specimens were surcharged equally, they have different states of over-consolidation during the testing. The results of such tests are frequently used to define a single failure envelope. Since the specimens behave differently under these testing conditions, and thus have different values of true cohesion, fitting them on one line is contradictory. This line will vary in relation to the testing conditions. Shear parameters, which are obtained from randomly distributed results of shear tests that depend upon contingencies are fictitious.

Results of shear tests carried out on partly saturated specimens can lead to additional errors when estimating the shear parameters. Suction in pore water could occur during the testing. This suction feigns high shear strength and falsifies the results.

Even if the actual shear parameters have been correctly obtained by accident for a particular stress state, the implication of these parameters in the stability calculation could still generate errors. Since the stress and overconsolidation states vary, because of the geometry, at every point along the sliding surface of a slope, the cohesion varies too (Figure 5).

It is therefore clearly incorrect to characterize the clay soil by a single set of strength parameters for slope stability calculations.

Furthermore, estimating shear parameters of cohesive soil by back-calculating from actual slope failures is also prone to error. In such calculations a substitute friction angle is obtained for every particular slice of the slope. The average of all substitute friction angles is then reported as the angle of internal friction of the soil. But since substitute angles depend upon $\sigma_{n}^{\prime}$ (Figure 6) for cohesive soil and because $\sigma_{n}^{\prime}$ varies at every point of the sliding surface, the obtained internal friction angle of the soil is fictitious, It applies only for that particular 

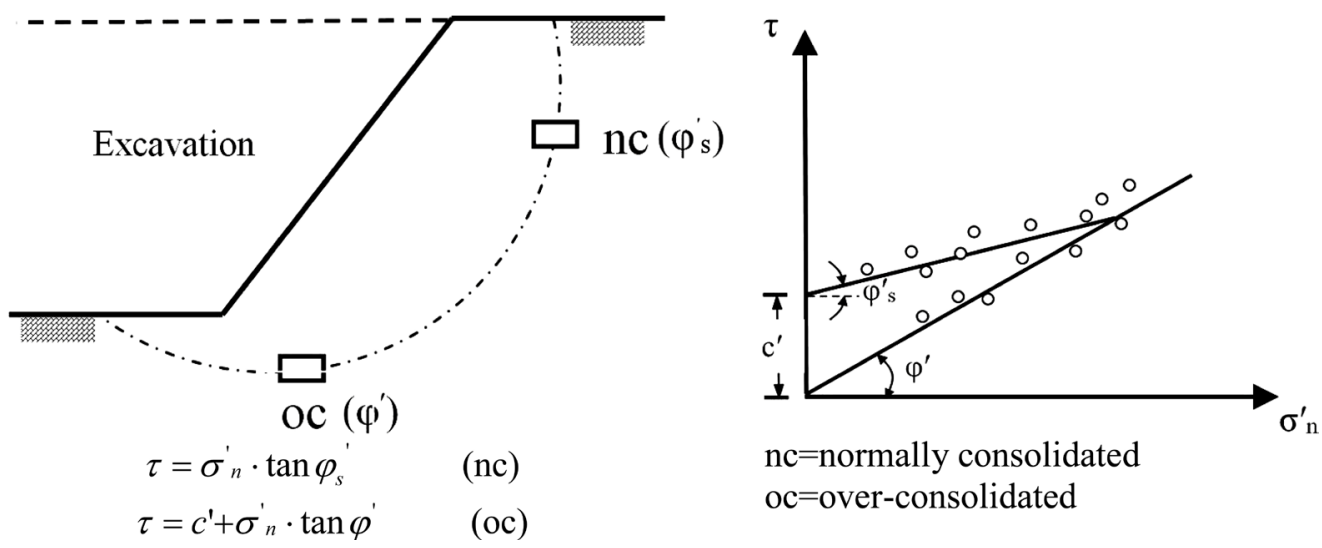

Figure 5. Example of the implication of shear parameters in the stability analysis of slopes.

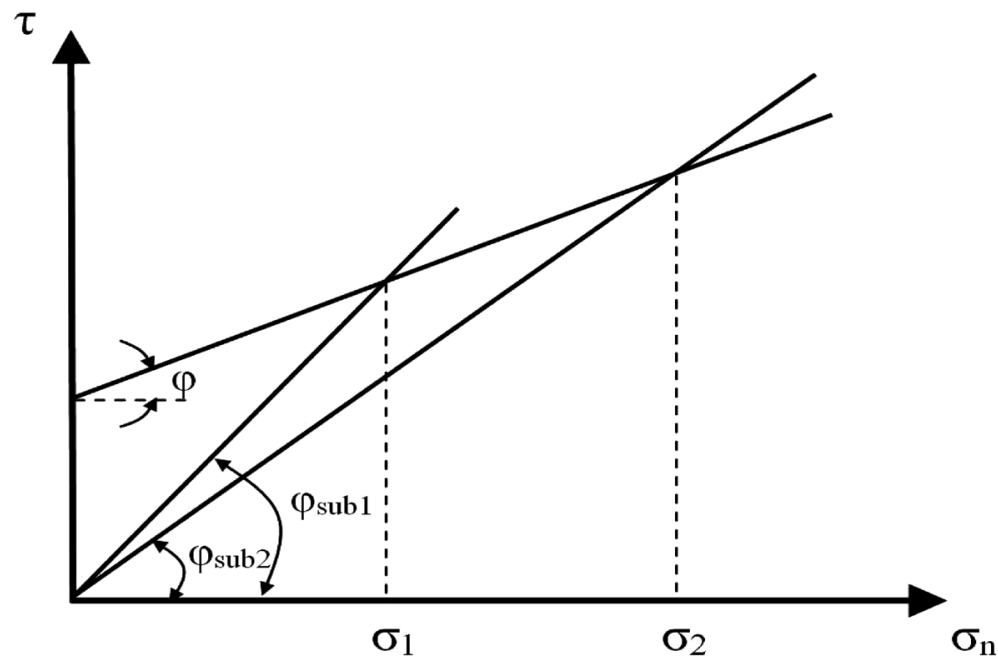

Figure 6. Definition of the substitute friction angle.

sliding surface.

By inference, the traditional shear box tests deliver results, which fit the Coulomb criterion from 1776 only. Although a contradiction exists between the traditional direct shear-box testing method and its implication in slope stability analysis, this method has lasted for a very long period of time.

\section{Modified Direct Shear Testing Criterion under Constant Volume}

Consolidation and shear tests on clayey specimens show that the soil deforms under the increment of load until it commences plastic flow. In this boundary state the material flows without changing its stress state. The volume deformation under load may consist of two parts: an elastic deformation $\delta^{e}$, which will be recovered after relieving the load and a plastic part of the deformation $\delta^{p}$ which is permanent (Figure 7).

The plastic deformation energy is dissipated internally in the form of friction between the particles [9] and thus it causes a change in the physico-mechanical properties of the material. This process is called hardening or softening of material, also see [10]. Soil specimens sheared in the shear box under constant normal load experience a plastic volume deformation and a shear deformation. The total work done per unit area is:

$$
\mathrm{d} W^{p}=\sigma_{n}^{\prime} \cdot \mathrm{d} V^{p}+\tau \cdot \mathrm{d} \gamma \quad \text { (constant load) }
$$

$V^{p}$ is equal to plastic volume deformation;

$\gamma$ is equal to shear deformation.

Depending upon the consolidation state of the soil, the volume deformation work is performed on or by the external normal stresses acting on the boundaries of the soil. Thus the internal stress state changes. In this case 
the measured shear stress is related to the external normal stress. Hence, the measured shear stress could be divided into two components:

$$
\tau_{\text {measured }}=\tau_{\text {extern }}+\tau_{\text {intern }}
$$

$\tau_{\text {extern }}$ is the part of the shear stress which is related to the normal stress causing the volume deformation, whilst $\tau_{\text {intern }}$ is the shear stress component generated by the internal friction. $\tau_{\text {extern }}$ may be positive or negative depending upon the degree of over-consolidation of the soil. In the case where shear tests are being performed under constant volume the total consumed work equals $\tau \cdot \mathrm{d} \gamma$. The work is always positive during shearing:

$$
\mathrm{d} W^{p}=\mu \cdot \sigma_{n}^{\prime} \cdot \mathrm{d} \gamma>0 \quad \text { (constant volume) }
$$

$\mu$ is equal to friction coefficient.

The influence of the plastic volume deformation shear strength, which is unknown, is eliminated in tests under constant volume. Figure 8 shows the relationship between $\tau, \sigma, \gamma$ in a shear test under constant volume.

For carrying out such tests under constant volume a special direct shear apparatus is needed. A modified ring shear apparatus, in which shear tests can be carried out under constant load as well as under constant volume, has been developed, built and tested by the author [11]. The testing procedure is relatively easy in this apparatus. After consolidating the soil specimen, of course under constant load, the volume control is activated during the shearing and the stress path ( $\sigma_{n}^{\prime}$ versus $\tau$ ) is plotted. Figure 9 shows an effective stress path of a ring shear test under constant volume of a normally consolidated specimen. The stress path ends at the critical state line (CSL), although the shearing continues. The material in the shear plane flows plastically in this state [12].

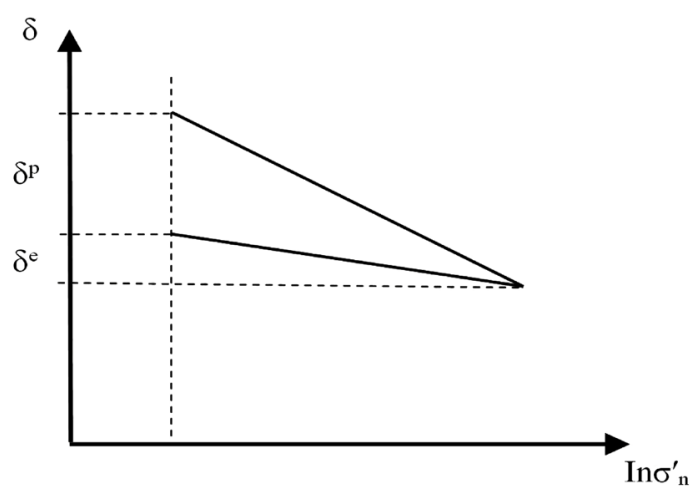

Figure 7. Deformation of soil under load.
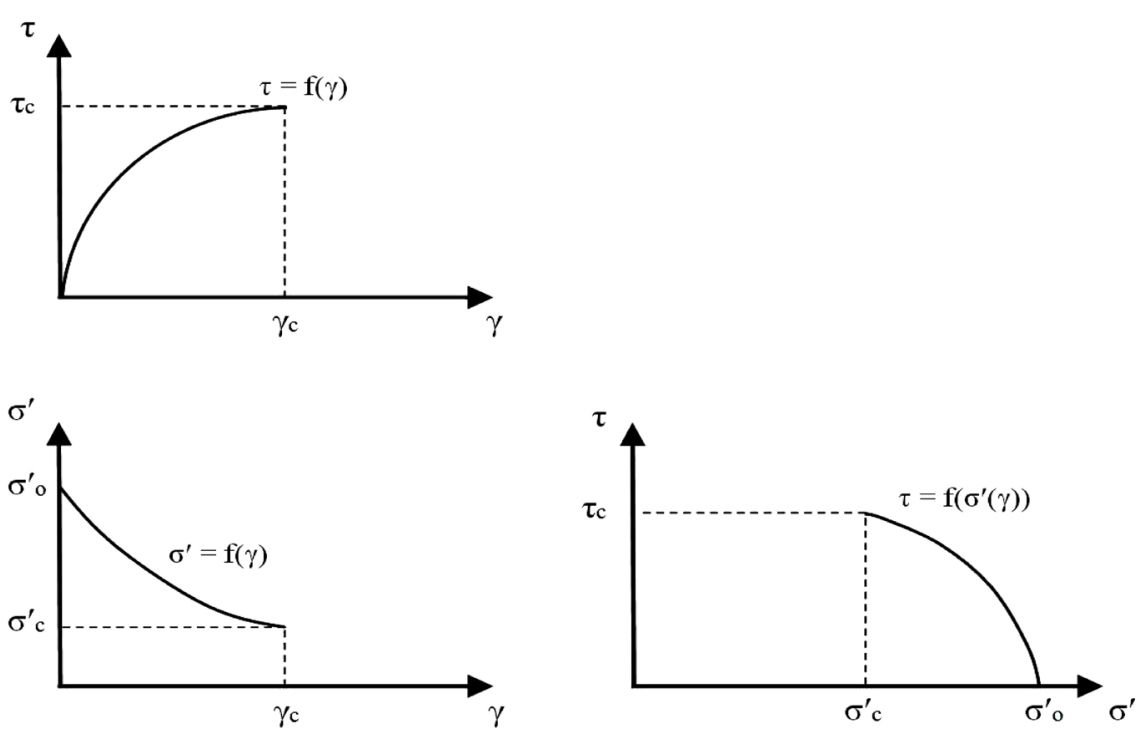

Figure 8. Relationships between $\tau, \sigma$ and $\gamma$ in a shear test under constant volume. 
$\tau$

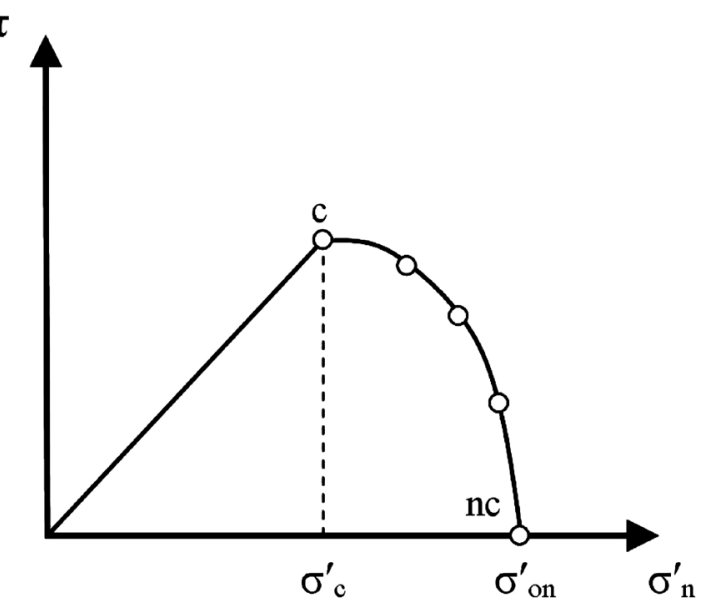

(a)

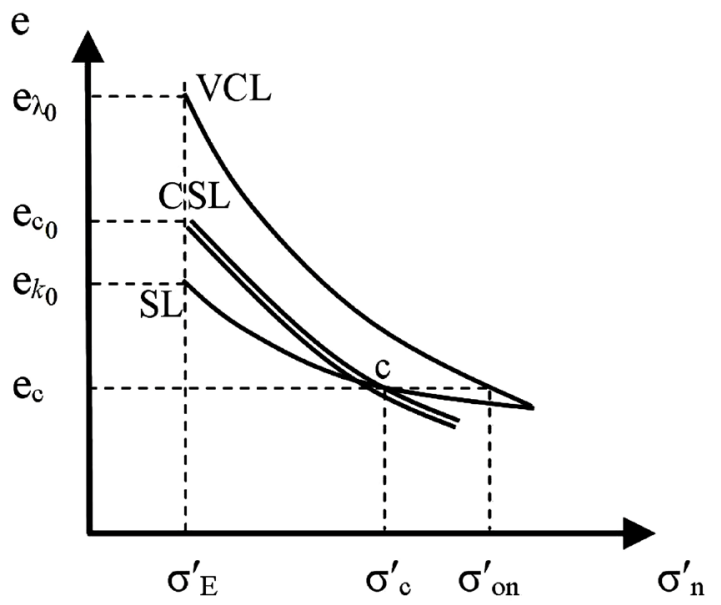

(b)

Figure 9. Effective stress path of a shear test under constant volume of a normally consolidated tuffitic specimen.

To establish the relevant shear parameters within this testing method it is necessary to investigate in particular the compression and shearing behavior mathematically.

From the diagram $9 \mathrm{~b}$ in which void ratio versus normal stress is graphed, the following relationship can be identified:

$$
e=e_{\lambda o}-\lambda \cdot \ln \left(\frac{\sigma^{\prime}}{\sigma_{E}}\right)
$$

with: $e$ is equal to void ratio at stress;

$e_{\lambda o}$ is equal to void ratio at unit load;

$\lambda$ is equal to slope of the VCL (virgin compression line) is equal to compression coefficient $\mathrm{Cc} / 2.3$;

$\sigma_{E}^{\prime}$ is equal to unit stress.

$$
e_{c}=e_{c_{o}}-\lambda \cdot \ln \left(\frac{\sigma_{c}^{\prime}}{\sigma_{E}^{\prime}}\right)
$$

From Figure 9(a)

$$
\tau=\mu \cdot \sigma_{c}^{\prime}
$$

with: $\mu$ is equal to friction coefficient.

and because the CSL is parallel to VCL (Figure 9(b)) for any given soil type, $\ln \sigma_{o_{n}}^{\prime}-\ln \sigma_{c}^{\prime}=\Delta$ is invariant

$$
\ln \sigma_{o_{n}}^{\prime}-\ln \sigma_{c}^{\prime}=\ln \left(\frac{\sigma_{o_{n}}^{\prime}}{\sigma_{c}^{\prime}}\right)=\Delta \text { soil specific constant }
$$

Substitution of (14) in (13) yields:

$$
\frac{\tau}{\sigma_{o_{n}}^{\prime}}=\mu \cdot \exp (-\Delta) \text { for normally consolidated soil }
$$

Because $\mu$ and $\Delta$ are both invariant for normally consolidated soil, the ratio $\tau / \sigma_{o_{n}}^{\prime}$ from Equation 15 is also a soil constant.

An over-consolidated specimen on SL (swell line) under $\sigma_{o}^{\prime}$ has the same void ratio as a normally consolidated one on VCL under the stress $\sigma_{e}^{\prime}$. Since the cohesion is a function of the void ratio for saturated soil both of these specimens have the same shear parameters. From Figure 10 the following equations are valid.

$$
e_{0}=e+k \ln \left(\frac{O C R \cdot \sigma_{0}^{\prime}}{\sigma_{0}^{\prime}}\right)
$$




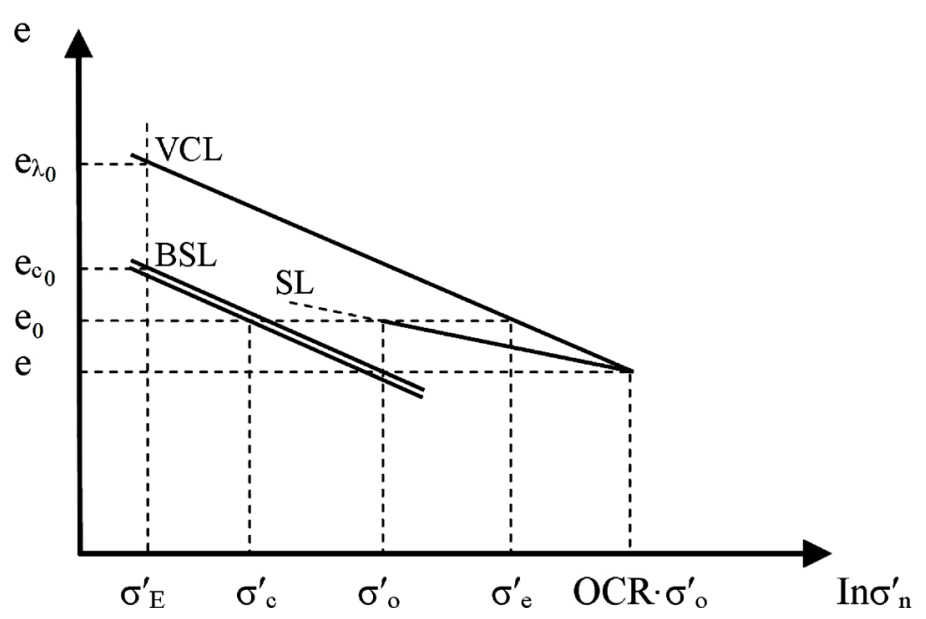

Figure 10. Void ratio versus normal stress.

and

$$
e_{0}=e+\lambda \ln \left(\frac{O C R \cdot \sigma_{0}^{\prime}}{\sigma_{e}^{\prime}}\right)
$$

where: $\kappa$ is equal to swell-coefficient in natural logarithm;

$O C R$ is equal to over-consolidation ratio.

The parameters $\lambda$ and $\kappa$ can be determined according to consolidation/swelling tests on reconstituted clay [13].

From both equations:

$$
\ln \sigma_{e}^{\prime}=\ln \left(O C R \cdot \sigma_{0}^{\prime}\right)-\kappa / \lambda \cdot \ln O C R
$$

or

$$
\sigma_{e}^{\prime}=O C R^{(1-k / \lambda)} \cdot \sigma_{0}^{\prime}=O C R^{\Delta_{0}} \cdot \sigma_{0}^{\prime}
$$

Since $(1-\kappa / \lambda)=\Delta_{0}$ is a specific soil parameter obtained from compression tests, the equivalent stress $\sigma_{e}^{\prime}$ is a function of the actual stress $\sigma_{0}^{\prime}$ and the $O C R$. Analogous to Equation (12) the following equations are valid for Figure 10:

$$
\begin{gathered}
e_{0}=e_{\lambda_{0}}-\lambda \cdot \ln \left(\frac{\sigma_{e}^{\prime}}{\sigma_{E}^{\prime}}\right) \\
\sigma_{e}^{\prime}=\sigma_{E}^{\prime} \cdot \exp \left(\frac{e_{\lambda_{0}}-e_{0}}{\lambda}\right)
\end{gathered}
$$

From (21) is obvious that $\sigma_{e}^{\prime}$ is a function of the void ratio too and thus $\sigma_{e}^{\prime}$ is a function of the cohesion. By standardizing the shear parameter obtained from shear tests carried out under constant volume over $\sigma_{e}^{\prime}$ and plotting the results, a shear line, which describes the shear behavior of the soil is obtained (Figure 11). Figure 11 shows the results of constant shear tests carried out on specimens of tuffitic sediments near Bonn.

The shear criterion becomes:

$$
\tau=\sigma_{n}^{\prime} \cdot \tan \varphi_{0}^{\prime}+K \cdot \sigma_{e}^{\prime}
$$

where $K$ is equal to cohesion coefficient (specific soil parameter) and thus the cohesion $c=K \cdot \sigma_{e}^{\prime} ;\left[c=f\left(\sigma_{e}^{\prime}\right)\right]$. With Equation 22 only two specific soil parameters ( $\varphi_{0}^{\prime}$ and $K$ ) exist and the shear strength of the soil is a function only of the actual load and $\sigma_{e}^{\prime}$ independent of the consolidation state.

By substituting Equations ((19) and (21)) in Equation (22) the following equations are obtained:

$$
\tau=\sigma_{n}^{\prime} \cdot \tan \varphi_{0}^{\prime}+K \cdot O C R^{\Delta_{0}} \cdot \sigma_{0}^{\prime}
$$

or 


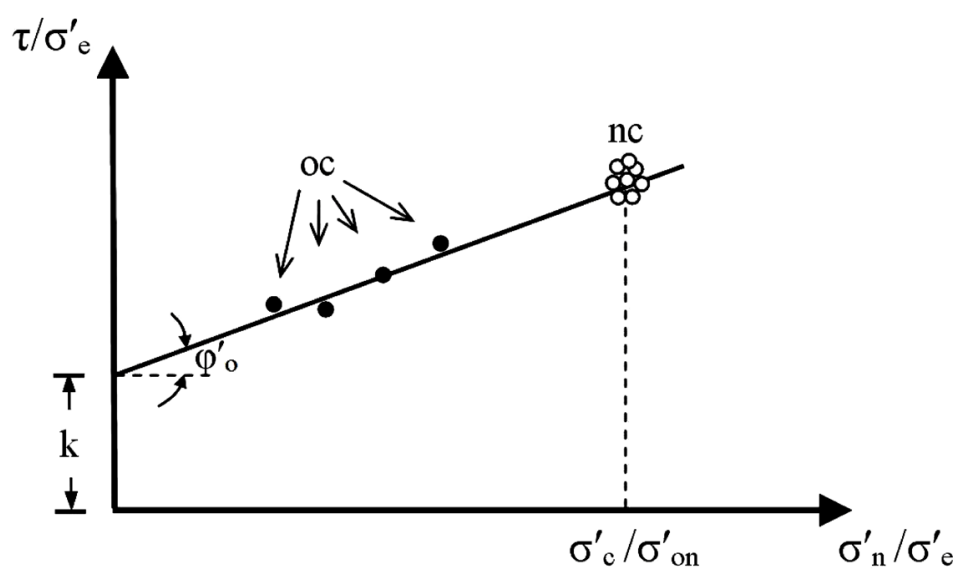

Figure 11. Standardized shear diagram of tuffitic soil.

$$
\tau=\sigma_{n}^{\prime} \cdot \tan \varphi_{0}^{\prime}+K \cdot \sigma_{E}^{\prime} \exp \left(\frac{e_{\lambda_{0}}-e_{0}}{\lambda}\right)
$$

Equation (15) is only valid for normally consolidated specimens. But since $\sigma_{0_{n}}^{\prime}$ (Figure 9(b)) can be generally replaced by $\sigma_{e}^{\prime}$ (Figure 10) for over-consolidated specimens, $\sigma_{0_{n}}^{\prime}$ of Equation (15) can be substituted by $\sigma_{e}^{\prime}$ of Equation (19) for over-consolidated soil resulting in:

$$
\frac{\tau}{O C R^{\Delta_{0}} \cdot \sigma_{0}^{\prime}}=\mu \cdot \exp (-\Delta) \rightarrow \frac{\tau}{\sigma_{0}^{\prime}}(\text { general })=\mu \cdot \exp (-\Delta) \cdot O C R^{\Delta_{0}}
$$

Because $\tau / \sigma_{0_{n}}^{\prime}$ in Equation (15) is invariant for a particular soil, Equation (25) can be standardized:

$$
\frac{\frac{\tau}{\sigma_{0}^{\prime}}(\text { general })}{\frac{\tau}{\sigma_{0_{n}}^{\prime}}(n c)}=O C R^{\Delta_{0}}
$$

Equations ((25) and (26)) show that the quotient of the shear strength over the initial stress under which the specimen has been consolidated and sheared is a function of the over-consolidation ratio OCR.

Equations ((22)-(24)) describe a criterion for shear parameters obtained from shear tests carried out under constant volume. It is obvious that this criterion describes the actual shear parameters and the elasto-plastic behavior of soil at every particular stress state. Because of the comprehensiveness of this criterion only few tests are required to establish the shear parameters. The stress paths of tests on normally and over-consolidated specimens can be arranged in a series with regard to the void ratio so that a 3-D structure is created. This 3-D structure (Figure 12) describes the shear behavior of that particular soil.

Stress states outside this structure do not exist.

\subsection{Direct Shear Testing Method under Constant Volume}

Since direct shear testing methods are popular for establishing shear strength parameters of cohesive soil because of several aspects, the author presents a modified direct shear testing technique and its criteria, which is adequate to describe the shear strength with regard to its elasto-plastic behavior of cohesive soil. He showed that soil specific shear parameters as well as the influence of plastic deformation on shear strength of cohesive soil can be established from few direct shear tests, carried out under constant volume. Realization of such particular testing conditions is beyond the capabilities of conventional box shear apparatus. However, efforts were directed towards the construction and testing of a new modified shear apparatus, which allows a wide range of testing conditions, including volume constancy. A ring shear testing principle was adopted, since it has some major advantages compared with traditional shear box testing. In the shear box a high stress concentration occurs at the cutting edge during shearing, whilst the stress distribution on the specimen is uniform in the ring shear apparatus. Furthermore, 
an infinite shear deformation can be implemented without decreasing the area subject to shearing.

The new modified ring shear apparatus utilizes state-of-the-art high technology including an electronically controlled system to achieve flexibility in the testing conditions and a high degree of reliability.

In the following, a brief technical description of the new ring shear apparatus is given and the testing procedure outlined.

\section{Technical Details and Description of the Apparatus}

The general principle of ring shear testing is based on setting one half of a normal-stressed ring specimen of soil in a rotary motion, whilst the other half is stationary. The shear force can then be easily established by measuring the torsion force (Figure 13).

Where shear testing of normally consolidated specimens is carried out under constant volume, a considerable drop of the normal load occurs in the course of testing. Therefore, the increment of the associated shear force can be very small. For monitoring such small increments without changes in volume, an accurate measuring system and precise instrumentation are needed. A technical realization of this principle therefore is essential. Against this background an electronic control system has been implemented in the design of the modified ring shear apparatus to achieve a high degree of reliability in the functioning of the different measuring system.

Technically, the rotary motion has been procreated by using a divider head of which, the handle was replaced by a gear motor. The revolution of this motor is monitored and controlled electronically. Thus, the shear rate of the specimen is continuously adjustable between $0.05 \mathrm{~mm} / \mathrm{h}$ and $85 \mathrm{~mm} / \mathrm{h}$.

The torsion force which is generated in the lower half of the tested specimen is measured by two precise "weight transducers". Since the measuring principle of these transducers is based on monitoring the deflectional

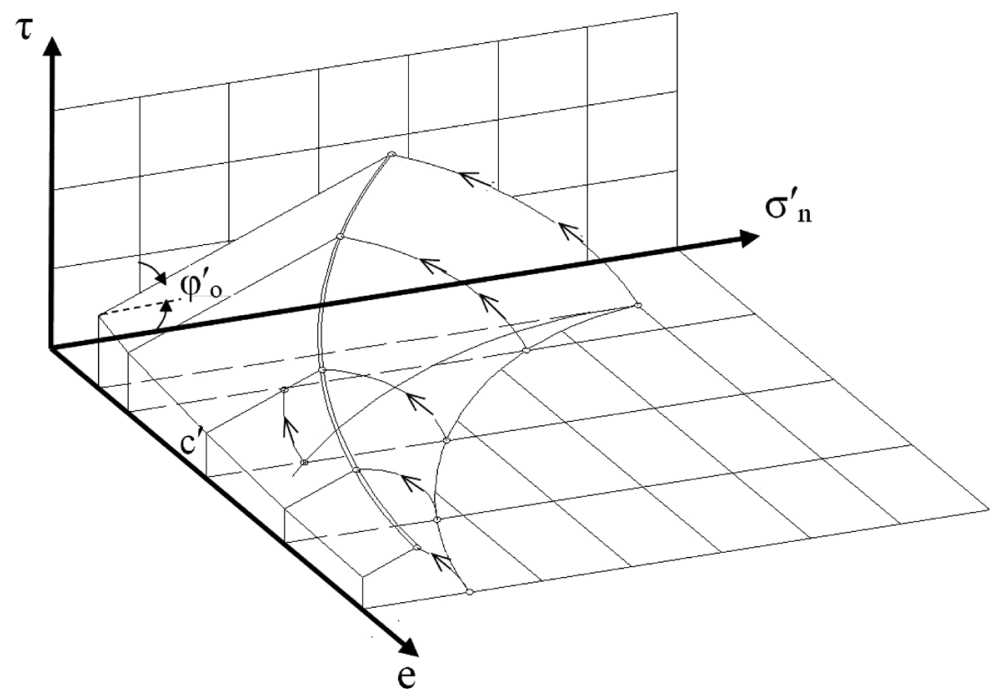

Figure 12. Paths of effective stresses versus void ratio (results obtained from tests on tuffitic soil specimens).

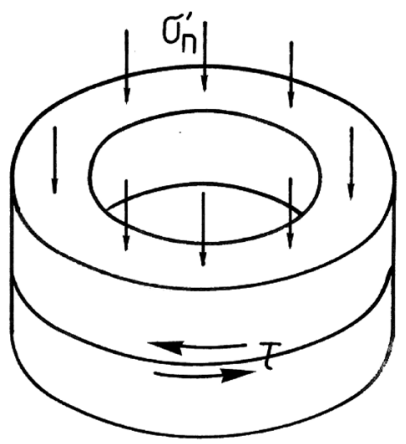

Figure 13. The general principle of ring shear testing. 
strain caused by point load acting on one end, they can be used for measuring torsion force directly (Figure 14(a)).

To allow specimens being tested under constant volume to consolidate under constant load before testing, a new feedback-controlled system has been developed and used. This system consists of three elements:

a) Stroke gear box driven by an electronically controlled motor;

b) Load transducer for measuring the actual normal load which acts through transmission shaft on the specimen;

c) Two precise "weight transducers" for measuring frictional forces generated between specimen and the brass shear head by dilation or contraction of the soil during shearing (only for testing under constant normal load). These forces act on or by the normal load.

The upper half of the shear head is carried by these two transducers, which are equipped with micrometer screws for adjusting the shear gap between the lower and the upper half of the shear head [14]. Thus, the upper half is floating with regard to the lower. In this case the frictional forces acting on the upper half can be monitored by the transducers directly (Figure 14(b)).

This feedback-controlled system may act as a constant-load and as a constant-volume system respectively. In the first case the desired load level is compared with the actual load measured by the load-transducer. As long as the feedback signal from the transducer is smaller than the required and adjusted signal, the motor of the stroke gearbox remains activated and increases the load. Conversely if the actual load is greater than the desired load the motor reverses and relieves the load. In this way a certain load level can be kept constant. Where testing is carried out under constant volume the system monitors the changes in normal load.

The shear head is designed to accommodate two different sizes of ring specimens. A small specimen with an
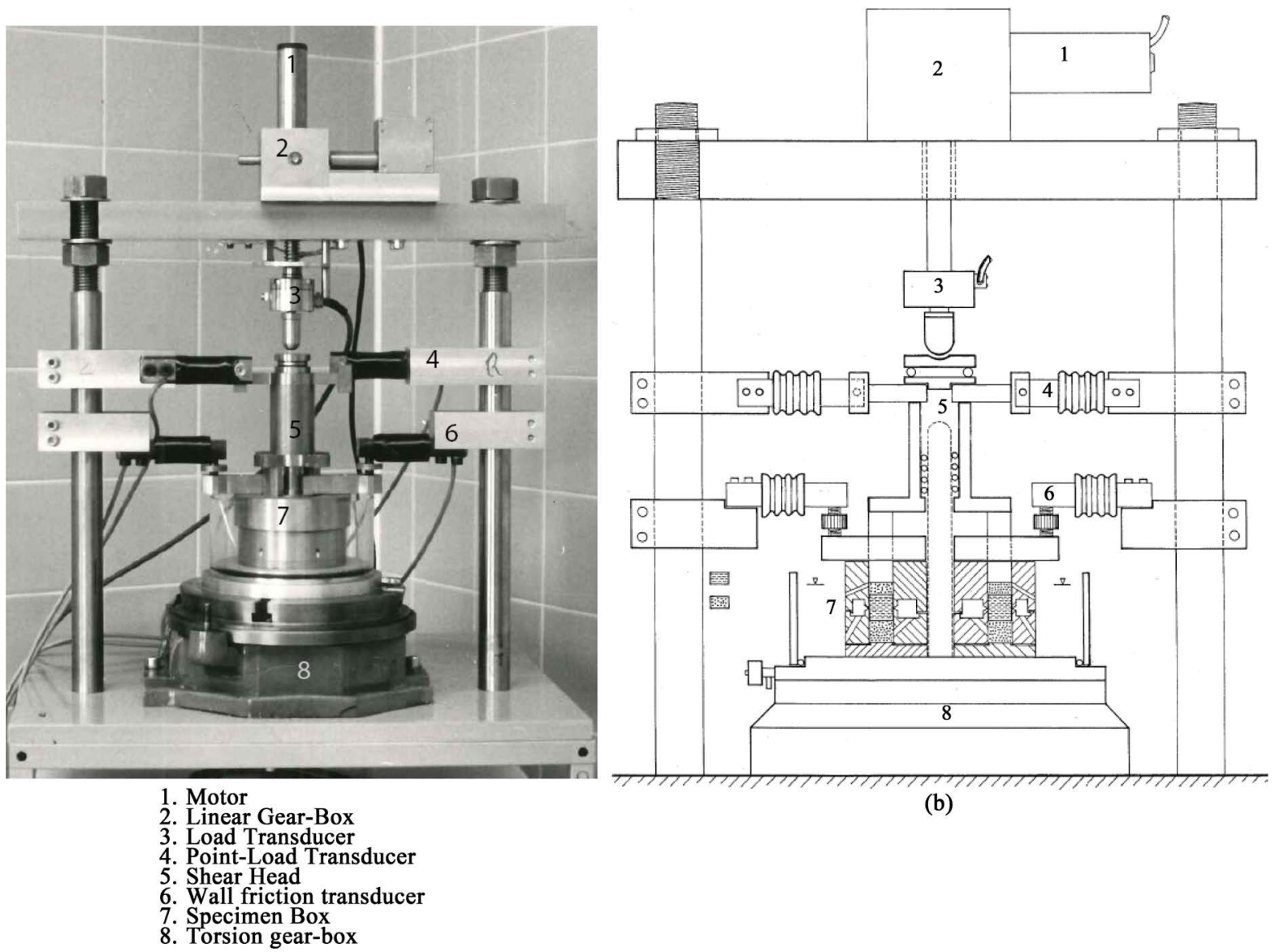

(b)

(a)

Figure 14. (a) Photo of the ring shear apparatus; (b) A picture and a schematic drawing of the ring shear apparatus (numbers are corresponding to Figure 14(a)). 
area of $20 \mathrm{~cm}^{2}$, (ID $\left.=49.9 \mathrm{~mm}, \mathrm{OD}=71 \mathrm{~mm}\right)$, and a bigger one with an area of $40 \mathrm{~cm}^{2}(\mathrm{ID}=70 \mathrm{~mm}, \mathrm{OD}=100$ $\mathrm{mm}$ ). The lower half of the shear head and the divider head are rigidly joined together so that both can be set in rotary motion, whilst the upper half is kept stationary by the weight transducers of the rotary system.

Metal filler on each side of the test specimen provides an effective drainage. To allow shear testing under water a perspex ring is placed round the shear head.

\subsection{Testing Procedure}

The modified ring shear apparatus is designed for testing of undisturbed as well as remoulded soil specimens.

A special device minimizes disturbance when undisturbed specimens are cut into rings and inserted into the shear head. The consolidation of both remoulded and undisturbed specimens is carried out under water to achieve a high degree of saturation. This is important especially for the testing of over-consolidated soil, since it develops water suction during the swelling process.

The testing program usually depends upon the aim of the investigation. If only the shear strength parameters of a certain soil are of interest, disturbed specimens are tested. In this case some few tests are carried out on normally consolidated specimens (theoretically, one test is sufficient if the consolidation behavior of the soil is known, otherwise two tests are needed) and a few tests on over-consolidated specimens (theoretically one is sufficient). The over-consolidation ratio is defined as the ratio of the maximum normal load to the load under which the specimen is sheared. From the results of these tests the shear criterion can be established (refer to [11] [15]). Where undisturbed specimens are tested, the over-consolidation ratio of every specimen can be established if, at best, one shear test is carried out on remoulded and normally consolidated specimens of the same soil type. The diagrams in Figure 15 should explain the relationships between the parameters.

By inference, the following points should explain the testing procedure when shear tests are carried out:

1) The disturbed soil should have water content of at least its liquid limit before consolidation;

2) A full consolidation must have occurred;

3) To achieve over-consolidation, specimens are to be stress-relieved to a smaller normal load under which they are to be sheared. During the relieving process, saturation must be maintained. Shearing should not be commenced until the relieving process is complete;

4) All specimens should be tested under water;

5) Undisturbed specimens should be saturated under normal load before shear testing;

6) The shear rate should be small enough to avoid development of water pressure.
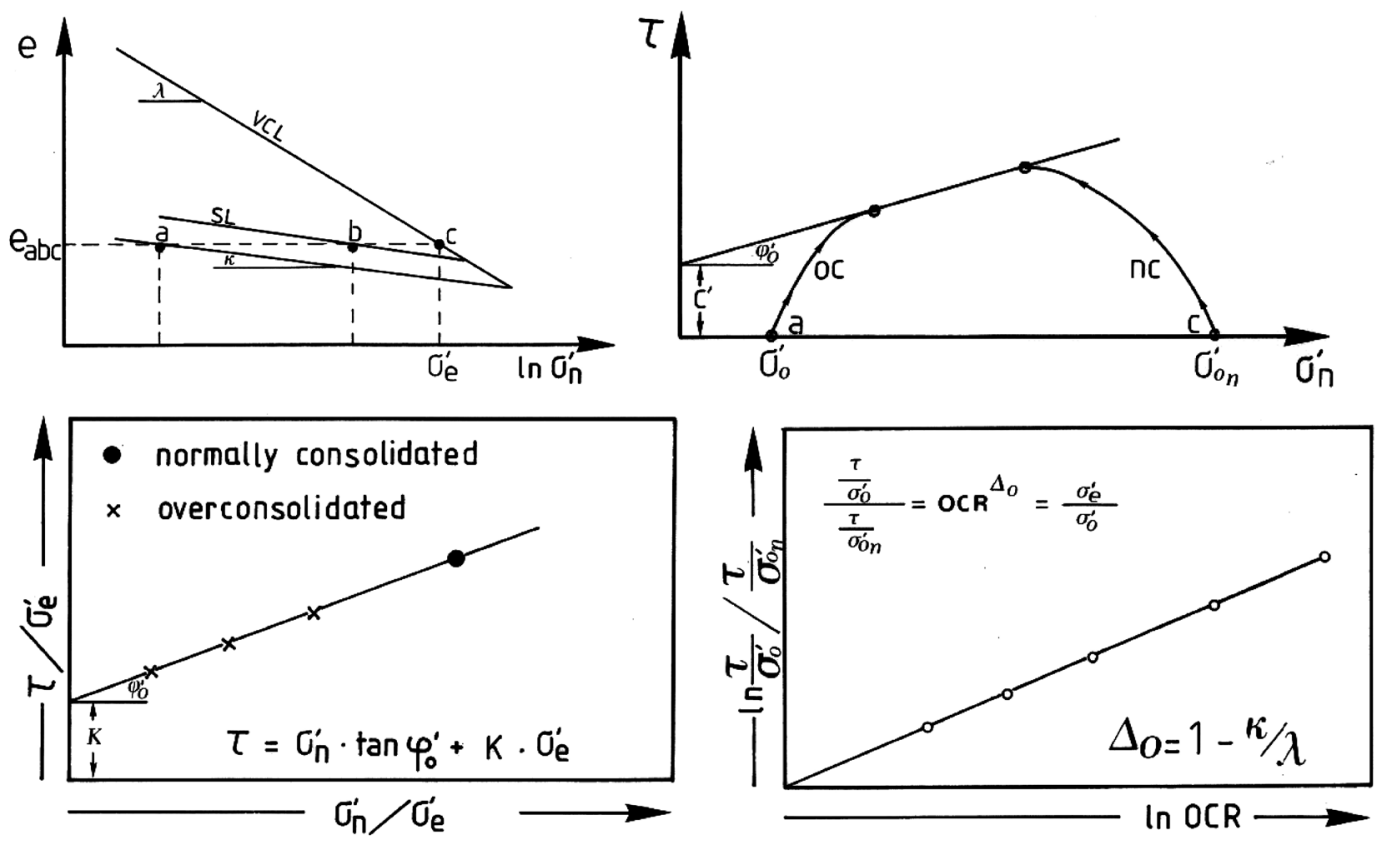

Figure 15. Relationships between the shear parameters. 
The stress paths of nc and oc specimens under different compression stresses and OCRs are obtained and can be processed according to Figure 15. From this Figure all necessary shear parameters are obtained.

\subsection{Results of the Tested Tuffitic Sediments}

Four shear testing campaigns under constant volume have been carried out under different conditions to establish the described relationships. The results according to equation 22 are shown in Figure 16.

The stress paths for the specimens of the soils M3 and M6 as normal and over-consolidated specimens are given in Figure 17.

For further processing of the results the standardized shear strengths are diagramed against the over- consolidation ratios for the soils M3 to M6 in Figure 18. From this relationship further parameters can be obtained.

If the shear strengths of over-consolidated specimens are standardize over the shear strength of normal- consolidated specimens for one soil and diagramed in a double logarithm graph, every soil type shows a typical curve of its own (Figure 19).

\section{Implication in Slope Stability Analysis}

The shear parameters $\varphi_{0}^{\prime}$ and $K$ of the presented criterion are specific soil parameters (true parameters), as mentioned before. They are invariant for a given soil. For incorporating these parameters in calculations of slope stability, a small modification of the equation is needed irrespective of which formula is being used, since $K$ is

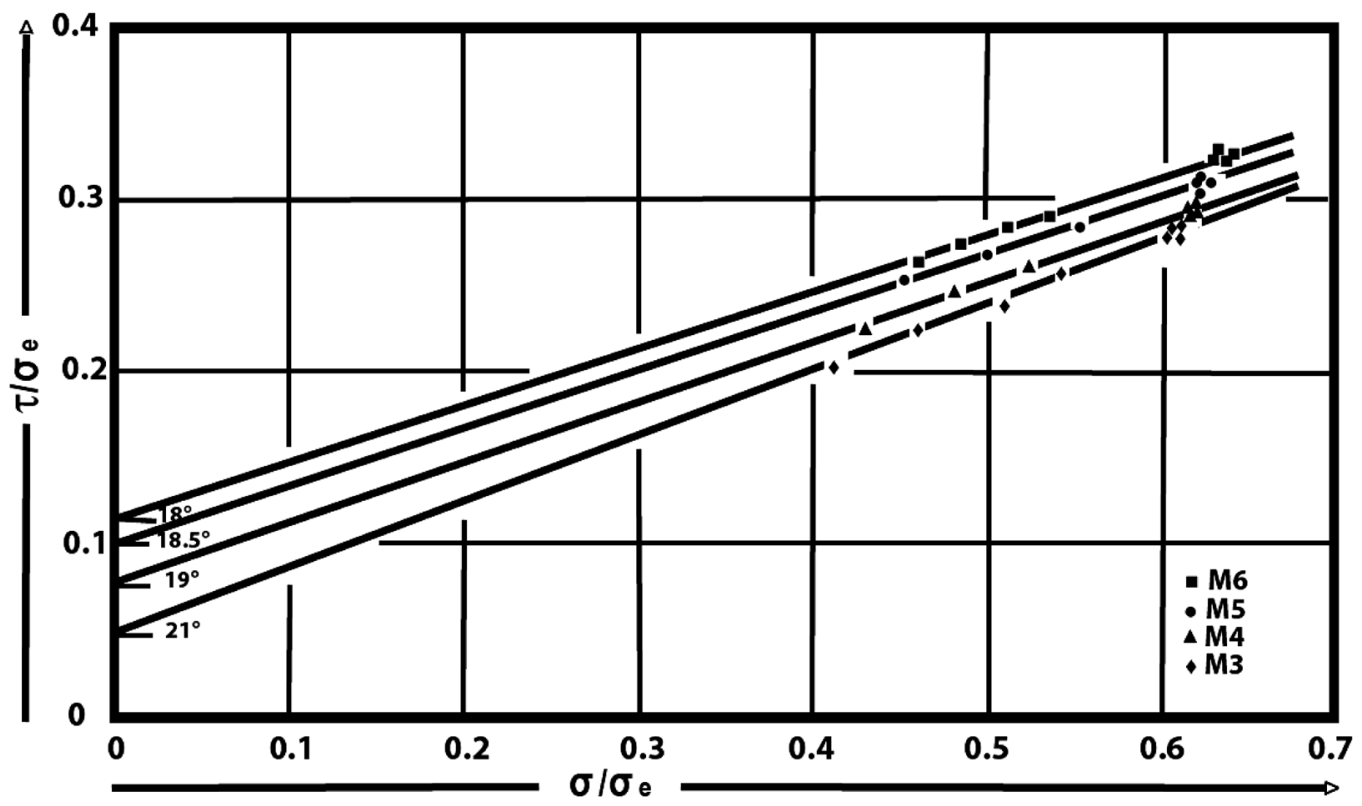

Figure 16. Standardized shear for the tuffitic soils M3 to M6 for nc and oc specimens.
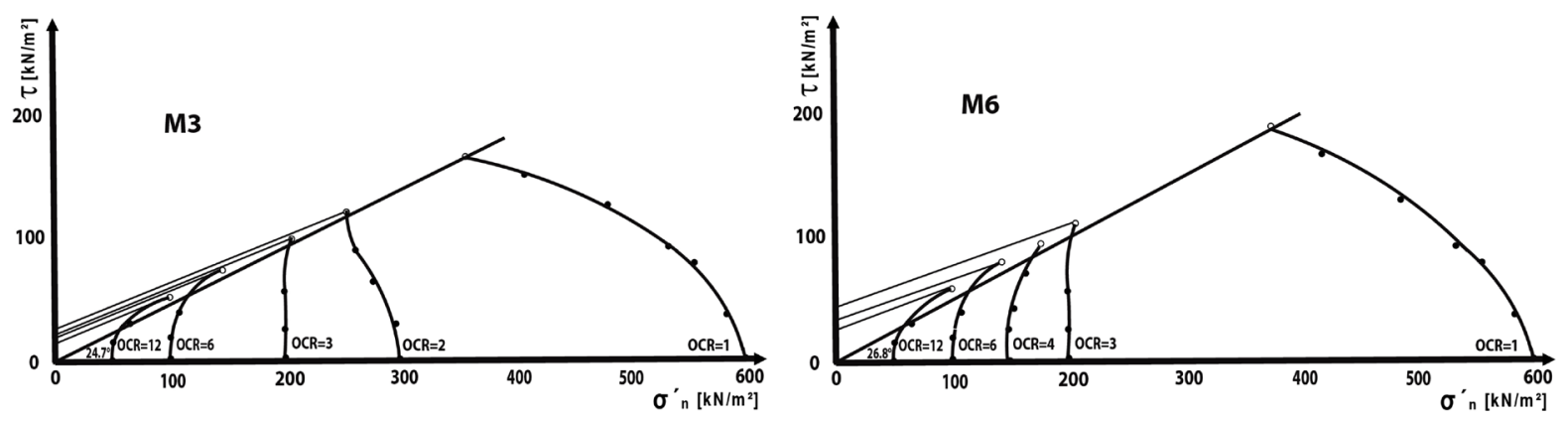

Figure 17. Stress paths for the specimens of the soils M3 and M6 exemplarily. 


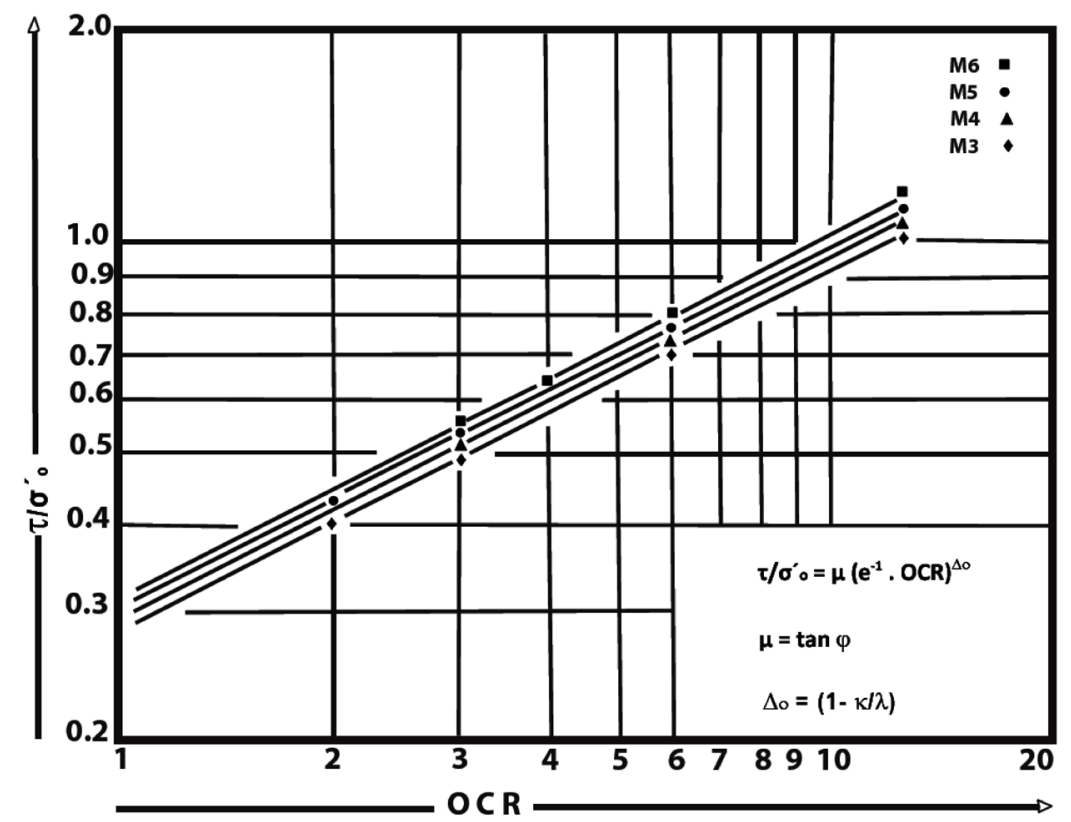

Figure 18. Relationship between standardized shear strength and over-consolidation ratio.

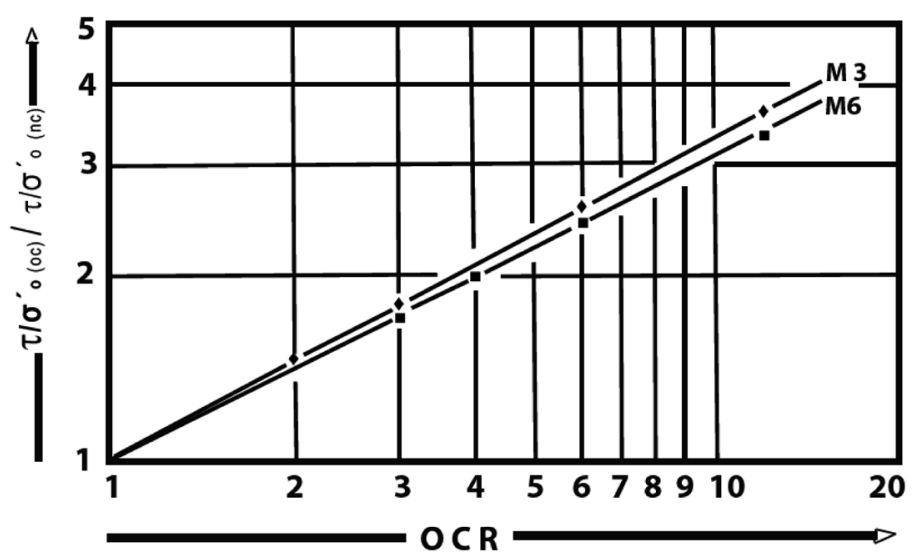

Figure 19. Standardized over-consolidated shear strengths over normal-consolidated shear strength versus over-consolidation ratio for the soils M3 and M6.

the cohesion coefficient and not the cohesion itself.

The slope, which is subject to a stability calculation should be divided into areas with similar properties and/or stress states, although this procedure is not needed if the slice-method is being used for the calculation. Since the shear strength in every slice depends not only on the stress and the friction angle $\varphi_{0}^{\prime}$, which is invariant, but also on the cohesion, the cohesion of every slice has to be calculated separately using the parameter $K$ and either $\sigma_{e}$ or $O C R^{\Delta_{0}} \cdot \sigma_{0}$ (Equations ((22) and (23))). The use of an iterative computer program simplifies this procedure. For more information about the choice of the method of stability analysis see [16].

An example should explain the procedure:

For the stability analysis after the cutting of the slope depicted in Figure 20 the well-known Janbu-Equation and Equation (23) are being used to substitute the cohesion:

$$
\eta=\frac{\sum \frac{(G-\Delta u b) \cdot \tan \varphi_{0}^{\prime}+\sigma_{e}^{\prime} \cdot K \cdot b}{\cos ^{2} \cdot \vartheta\left(1+1 / \eta \cdot \tan \vartheta \cdot \tan \varphi_{0}^{\prime}\right)}}{\sum G \cdot \tan \vartheta} \rightarrow \eta=\frac{\sum \frac{(G-\Delta u b) \cdot \tan \varphi_{0}^{\prime}+O C R^{\Delta_{0}} \cdot(G-\Delta u b) \cdot K \cdot b}{\cos ^{2} \cdot \vartheta\left(1+1 / \eta \cdot \tan \vartheta \cdot \tan \varphi_{0}^{\prime}\right)}}{\sum G \cdot \tan \vartheta}
$$




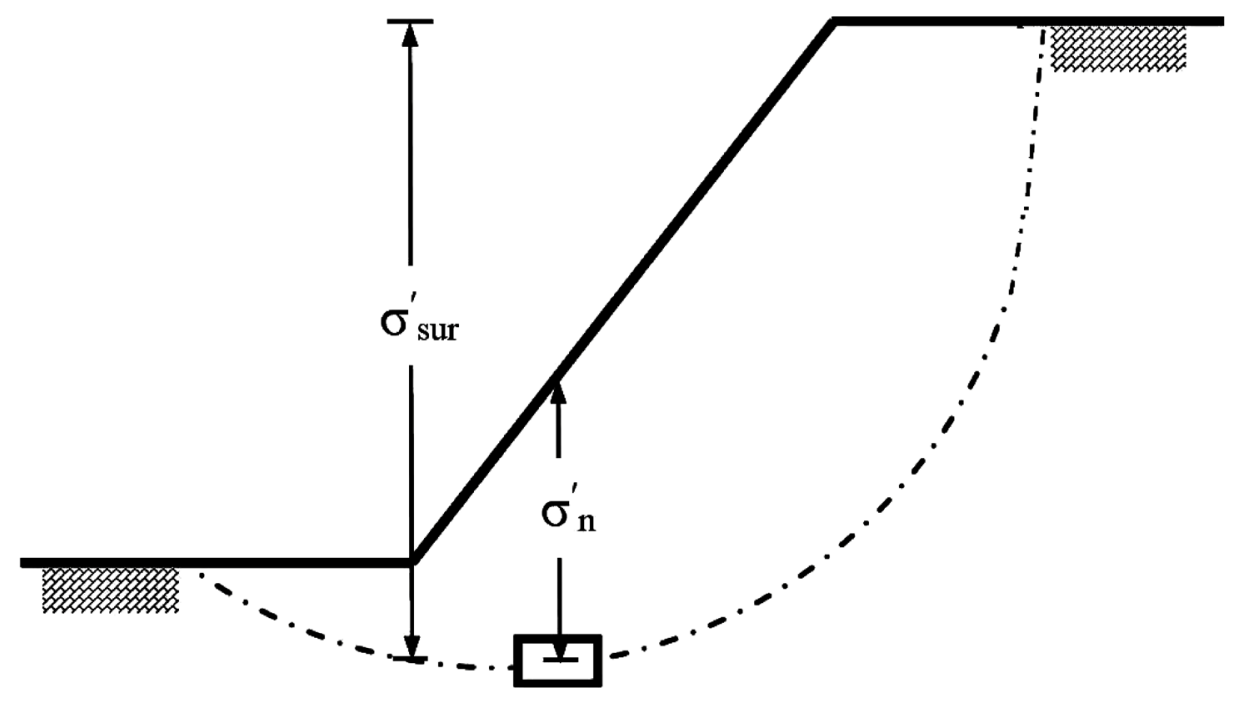

Figure 20. Example of a slope.

From a few shear tests under constant volume the true parameters $\varphi_{0}^{\prime}$ and $K$ are established for that particular soil. The parameter $\Delta_{0}$ can be calculated from Equation (26) or established from compression tests. For the calculation of the stability of every slice the OCR can be determined from Equation (28).

$$
O C R=\frac{\sigma_{s u r}^{\prime}}{\sigma_{n}^{\prime}}
$$

The actual weight of the slice before and after the cutting can be determined easily from the geometry of the slope and is required in any case for the calculations. Equation (27) considers the stress state of every slice separately and calculates its actual cohesion.

\section{Conclusion}

The use of the cohesion in slope stability analysis determined in direct shear tests according to Coulomb shear criterion may lead to over estimation since it does not reflect the long-term true behavior of clayey soil. Therefore many scientists suggest reduction of the cohesion for long-term determination of the safety factor. The criterion described in this paper considers the final cohesion under the actual stress state. Because the true shear parameters are established from results of shear tests carried out on saturated specimens under effective stresses and since the slope stability calculations are considering the actual stress state and thus the actual cohesion after swelling at every point, long term changing of the stress state and cohesion of the soil due to load relieving and swelling effects, after cutting the slope, which often leads to slope failure after some years, has been taken into account and therefore the stability calculations are infinitely valid. An empirical reduction of the cohesion or the safety factor for long-term stability, as has been recommended by authors in the past [17], is therefore not needed.

\section{Acknowledgements}

The laboratory tests have been carried out in the soil laboratory of the Department of Engineering Geology, RWTH Aachen University. I would like to thank Mr. Bernd Meyer, the laboratory technician for his support in the lab.

\section{References}

[1] Coulomb, C.A. (1776) Essai sur une application des regles de maximis et minimis quelques problemes de statique, relatits a l'architecture. Memoires de Mathematique de l'Academie Royale de Science 7, Paris.

[2] Skempton, A.W. (1949) Alexandre Collin, 1808-1890: A Note on His Pioneer Work in Soil Mechanics. Geotechnique, $1,216$. 
[3] Krey, H. (1927) Rutschgefahrliche und flieende Bodenarten. Baut, 5, 485.

[4] Tiedeman, B. (1932) Die Bedeutung des Bodens im Bauwesen. In: Blank, E., Ed., Handbuch der Bodenlehre, Band 10, Springer Verlag, Berlin.

[5] Hvorslev, M.J. (1936) Conditions of Failure for Remoulded Cohesive Soil. Proceedings of the 1st International Conference on Soil Mechanics and Foundation Engineering, Cambridge, 22-26 June 1936, 51-53.

[6] Hvorslev, M.J. (1937) Ueber die Festigkeitseigenschaf ten gestörter bindiger Boden. Ingenioervidensk. Ingenieurvidenskabelige Skrifter, Copenhagen.

[7] Ohde, J. (1949) Vorbelastung und Vorspannung des Baugrundes und ihr Einfluxt auf Setzung, Festigkeit und Gleitwiderstand. Baut, 26, 129, 163.

[8] Skempton, L.W. (1951) The Measurement of the Shear Strength of Soil. CMSS, 2, 90.

[9] Hardin, B.O. (1978) The Nature of Stress-Strain Behaviour for Soils. Proceedings of Earthquake Engineering and Soil Dynamics, ASCE, Pasadena, 19-21 June 1978, 3-89.

[10] Mitchell, J.K. and Mc Connell, J.R. (1965) Some Characteristics of the Elastic and Plastic Deformation of Clay on Initial Loading. Proceedings of the 6th International Conference on Soil Mechanics and Foundation Engineering, 5, 313317.

[11] Azzam, R. (1986) Modified Ring Shear Apparatus. Technical Note Internal Report. (Unpublished)

[12] Schofield, A. and Wroth, P.I. (1968) Critical State Soil Mechanics. Mc Craw-Hill, London.

[13] Yao, Y., Gao, Z., Zhao, J. and Wan, Z. (2012) Modified UH Model: Constitutive Modeling of Over-Consolidated Clays Based on a Parabolic Hvorslev Envelop. Journal of Geotechnical and Geoenvironmental Engineering, 138, 860868.

[14] Bishop, A.I., Green, G.E., Garga, V.K., Andersen, A. and Brown, J.D. (1971) A New Ring Shear Apparatus and Its Application to the Measurement of Residual Strength. Geotechnique, 21, 273-328. http://dx.doi.org/10.1680/geot.1971.21.4.273

[15] Azzam, R. (1984) Experiinentelle und theoretische Untersuchungen zum Quell, Kompressions und Scherfestigkeitsverhalten tuffitischer Sediniente und deren Bedeutung für die Standsicherheitsanalyse tiefer Einschnittsbbschungen. Mitteilung zur Ing und Hydrogeologie, Aachen, Heft 18.

[16] Bishop, A.W. (1971) The Influence of Progressive Failure on the Choice of the Method of Stability Analysis. Geotechnique, 21, 168-172. http://dx.doi.org/10.1680/geot.1971.21.2.168

[17] Skempton, A.W. (1964) Long Term Stability of Clay Slopes. Geotechnique, 14, 77-107. http://dx.doi.org/10.1680/geot.1964.14.2.77

\section{Submit or recommend next manuscript to SCIRP and we will provide best service for you:}

Accepting pre-submission inquiries through Email, Facebook, LinkedIn, Twitter, etc.

A wide selection of journals (inclusive of 9 subjects, more than 200 journals)

Providing 24-hour high-quality service

User-friendly online submission system

Fair and swift peer-review system

Efficient typesetting and proofreading procedure

Display of the result of downloads and visits, as well as the number of cited articles

Maximum dissemination of your research work

Submit your manuscript at: http://papersubmission.scirp.org/ 